\title{
ESTAQUIA E EFEITO DA DEFICIÊNCIA HÍDRICA OU INUNDAÇÃO SOBRE CARACTERÍSTICAS MORFOANATÔMICAS DE Cestrum axillare Vell.
}

\section{CUTTING AND EFFECT OF THE WATER DEFICIT OR FLOODING ON MORPHOANATOMIC CHARACTERISTICS OF Cestrum axillare Vell.}

\author{
Lucas Amaral de Melo ${ }^{1}$ Hyrandir Cabral de Melo $^{2}$ Antonio Claudio Davide ${ }^{3}$ \\ Evaristo Mauro de Castro ${ }^{4}$ Juliano de Paulo dos Santos ${ }^{5}$
}

\begin{abstract}
RESUMO
O estudo do ecossistema de matas ciliares tem sido alvo de inúmeros trabalhos e pesquisas nos últimos anos. Porém, pelas condições microclimáticas dessas áreas, pouco se conhece a respeito das espécies com potencial para utilização em projetos de recuperação florestal, uma vez que, no mesmo local, pode haver condições de deficiência hídrica e inundações ao longo de um ano. Além disso, buscar alternativas para o plantio de mudas à beira de cursos d'água é essencial, uma vez que se trata de um ambiente muito propício à erosão, sendo o plantio por meio de estacas uma forma de evitar o revolvimento do solo. Assim, o objetivo deste trabalho foi avaliar o potencial de enraizamento de estacas caulinares de Cestrum axillare Vell. e sua plasticidade morfoanatômica em condições de deficiência hídrica ou inundação do sistema radicular, a fim de verificar sua potencialidade de utilização em projetos de recuperação de matas ciliares. Para isso, foram confeccionadas estacas a partir de ramos coletados de uma planta matriz, as quais foram distribuídas em diferentes classes de diâmetro, e colocadas em substrato para enraizar. Depois de enraizadas, as mudas foram cultivadas em vasos de $4000 \mathrm{~cm}^{3}$ de volume e, aos quatro meses de idade, submetidas aos tratamentos de deficiência hídrica ou inundação do sistema radicular. As avaliações foram realizadas ao longo de todo o estudo, desde observações visuais até a quantificação das alterações morfoanatômicas por meio da análise de lâminas histológicas. A partir dos resultados obtidos, verificou-se que Cestrum axillare pode ser propagada pela técnica de estaquia e é uma espécie indicada para ser utilizada em projetos de recuperação de matas ciliares.
\end{abstract}

Palavras-chave: mata ciliar; raízes adventícias; lenticela; coerana.

\begin{abstract}
The ecosystem of riparian forests has been the subject of numerous studies and research in recent years. However, due to microclimate conditions in these areas, little is known about the species with potential for use in forest restoration projects, since in the same place, it may be conditions of low water availability and floods over a year. Also, the search for alternatives for the planting of seedlings in river borders is essential since it is an enabling environment to erosion, and planting by cuttings is a possibility because there is no need for soil disturbance. Thus, the objective of this study was to evaluate the potential of rooting of stem cuttings of Cestrum axillare Vell. and its morphological and anatomical plasticity in conditions of low availability of water or inundation of root system in order to verify its potential for use in restoration projects

1 Engenheiro Florestal, Dr., Professor Adjunto do Departamento de Ciências Florestais, Universidade Federal de Lavras, Campus da UFLA, CEP 37200-000, Lavras (MG), Brasil. lucas.amaral@dcf.ufla.br

2 Licenciado em Ciências Agrícolas, Dr., Professor Adjunto do Instituto de Ciências Biológicas, Universidade Federal de Goiás, Campus Samambaia, CEP 74001-970, Goiânia (GO), Brasil. hyrandir@yahoo.com.br

3 Agrônomo, Dr., Professor Titular do Departamento de Ciências Florestais, Universidade Federal de Lavras, Campus da UFLA, CEP 37200-000, Lavras (MG), Brasil. acdavide@dcf.ufla.br

4 Engenheiro Florestal, Dr., Professor Associado do Departamento de Biologia, Universidade Federal de Lavras, Campus da UFLA, CEP 37200-000, Lavras (MG), Brasil. emcastro@dbi.ufla.br

5 Engenheiro Florestal, Doutorando do Programa de Pós-graduação em Engenharia Florestal, Universidade Federal de Lavras, Campus da UFLA, CEP 37200-000, Lavras (MG), Brasil. juliano_engflorestal@yahoo.com.br
\end{abstract}


in riparian environments. For that, cuttings were made from a matrix plant in different diameter classes and placed to root. After rooted, the plantlets were planted in containers of $4000 \mathrm{~cm}^{3}$ and at four months of age, subjected to low availability of water or flooding of root system. Evaluations were conducted throughout the study, covering visual observation and quantification of morphological and anatomical changes through histological sections. From the results, it was found that Cestrum axillare has potential to be propagated by cutting technique and it is indicated for use in restoration of riparian forest projects.

Keywords: riparian forest, adventitious roots; lenticels; coerana.

\section{INTRODUÇÃO}

A mata ciliar é uma formação florestal bastante variável e seus aspectos florístico e estrutural são influenciados por uma série de fatores, especialmente relacionados à umidade do solo, à profundidade do lençol freático, à frequência de alagamentos e à disponibilidade de oxigênio no solo (CALLEGARO et al., 2012; CASTRO; CASTRO; SOUZA, 2013). Além disso, devido a sua localização em terras mais férteis, essa vegetação sofre, em geral, grande pressão antrópica, e por este motivo muitas áreas encontram-se em diferentes níveis de degradação (FERREIRA; DIAS, 2004). É possível, ainda, na época das chuvas, a ocorrência de inundações periódicas com elevação do lençol freático e consequente redução de oxigênio no solo (MARINHO et al., 2013). Enquanto em períodos de seca, o nível da água pode baixar consideravelmente, levando o ambiente a uma condição desfavorável de suprimento de água para as plantas (SILVA et al., 2001).

Desta forma, tendo em vista a recomposição florestal nesses locais, é importante conhecer as espécies vegetais que se adaptem aos fatores ambientais contrastantes ocorrentes ao longo do ano, principalmente relacionados às condições de inundação e deficiência hídrica. Assim, uma vez determinadas as espécies, o plantio de mudas e/ou de estacas pode ser uma alternativa eficiente (CASEMIRO; MALAVASI; MALAVASI, 2008), visto que a revegetação por semeadura direta é mais difícil nesses locais (SANTARELLI, 1996). Dependendo das circunstâncias, o estaqueamento pode ser a melhor possibilidade por não haver necessidade de revolvimento do solo e ou abertura de covas.

A estaquia é uma técnica de propagação vegetativa amplamente empregada em espécies de valor comercial e pode ser viável para propagar espécies nativas de mata ciliar, dependendo da facilidade de enraizamento de cada espécie, da qualidade do sistema radicular formado e do desenvolvimento posterior da planta (SANTOS et al., 2011). Como princípio básico, para o sucesso na revegetação de matas ciliares pela utilização da técnica de estaquia, é necessário que a espécie apresente facilidade de enraizamento (SANTARELLI, 1996; DIAS et al., 2012). Experimentos realizados com propagação de plantas visando à recuperação de mata ciliar, a exemplo do que foi observado com sarandi-branco (Phyllanthus sellowianus Müll. Arg.), vime (Salix viminalis L.) e urana (Alchornea castaneifolia (Willd.) A. Juss.), mostraram que estas espécies apresentam-se potencialmente aptas para a revegetação das margens de cursos de água, a julgar pelo seu alto percentual de pega, ressaltando-se os efeitos de diferentes substratos sobre o percentual de sobrevivência das mudas (SUTILI et al., 2004; PAULA; PAIVA; MARANHO, 2013). Outras espécies nativas regionais também podem ser utilizadas com o mesmo propósito, como Cestrum axillare Vell., vulgarmente chamada de coerana, conforme elucidado por Santos et al. (2011).

De acordo com a Lista de Espécies da Flora do Brasil, Cestrum axillare é uma espécie arbórea, pertencente à família Solanaceae que ocorre em todos os domínios fitogeográficos do Brasil, em 18 unidades da federação e nos tipos de vegetação Floresta Estacional Semidecidual, Floresta Ombrófila e Restinga. A espécie apresenta oito sinônimos relevantes, com destaque ao nome Cestrum laevigatum Schlechtd (STEHMANN et al., 2014). Andrade et al. (2006) a reconhecem como uma espécie de ocorrência exclusiva na faixa de maior umidade do solo (20 m a partir do curso d'água no sentido da encosta), em matas ciliares de brejo de altitude no município de Areias, localizado na Paraíba e, ainda, de acordo com Pinto et al. (2005), é indicada em estratégias de restauração florestal desde solos bem-drenados, até solos úmidos ou encharcados de nascentes perturbadas, conforme estudo realizado na região de Lavras, em Minas Gerais. Essas informações de distribuição geográfica e preferência por habitat a qualificam como generalista, ocorrendo naturalmente em áreas ripárias.

Neste contexto, diferentes mecanismos de adaptação ou tolerância de plantas ao alagamento devem 
ser observados nas espécies a serem implantadas em ambientes alagáveis. Dentre as estruturas anatômicas que contribuem para tolerância de plantas a uma condição prolongada de alagamento destacam-se as raízes adventícias, os aerênquimas e as lenticelas. As raízes adventícias são formadas em certas espécies, quando estas são submetidas à inundação, atuando como uma estratégia adaptativa para substituir as raízes velhas que sofrem processos oxidativos (MEDRI et al., 1998; PAROLIN, 2001). Parênquimas de reserva de ar (aerênquimas) em raízes também são de fundamental importância para a sobrevivência das plantas, atuando como uma reserva de oxigênio para a respiração aeróbica das raízes mesmo durante períodos de inundação (WANG; CAO, 2012). De forma complementar, as lenticelas hipertrofiadas caulinares, ricas em espaços aéreos intercelulares, são importantes para o suprimento de oxigênio necessário à respiração, o qual é proveniente da atmosfera ou de órgãos fotossintetizantes, e que pode chegar às raízes pelas interconexões aéreas presentes nos tecidos caulinares e radiculares (KREUZWIESER; RENNENBERG, 2014). Além disso, as lenticelas podem atuar na eliminação de substâncias tóxicas voláteis produzidas durante os processos fermentativos típicos que podem ocorrer em um ambiente pobre em oxigênio, a exemplo do etanol (DAVANSO et al., 2002). Tanto aerênquima, quanto lenticelas são estruturas constitutivas, mas que quantitativamente podem aumentar em plantas inundadas e, portanto, atuar como mecanismos de tolerância à condição de inundação (DAVANSO et al., 2002).

Para revegetação de mata ciliar, além de características de tolerância ao alagamento, as plantas também devem apresentar características de tolerância à deficiência hídrica. Diferentes estratégias morfoanatômicas podem ser utilizadas pelas plantas, dentre as quais a redução da área foliar, a diminuição do tamanho dos estômatos e a diminuição do índice estomático contribuem para redução da transpiração, e, portanto, para o aumento da eficiência do uso da água (MAES et al., 2009; RIBEIRO et al., 2012). Algumas espécies podem aumentar a densidade estomática na condição de deficiência hídrica, assim como uma redução no tamanho de seus estômatos, visando manter a regulação térmica promovida pela transpiração, ao mesmo tempo em que diminuem a perda de vapor de água pela diminuição do tamanho ou pela diminuição da abertura do ostíolo (MELO et al., 2007). As plantas também podem se utilizar de estratégias de escape de perda de água excessiva a exemplo da abscisão foliar, a qual pode ser programada ou ser desencadeada pela própria condição de deficiência hídrica (DOSMANN et al., 1999). O aumento na espessura do mesofilo é uma estratégia que pode contribuir para evitar danos fotoxidativos, cuja suscetibilidade aumenta na condição de deficiência hídrica (RENNENBERG et al., 2006). O aprofundamento das raízes para manter a absorção de água suficiente para suprir a demanda da planta é outra estratégia importante para garantia de sobrevivência a longos períodos de estiagem (SANTOS, 2011).

Com base no exposto, o objetivo deste trabalho foi avaliar o potencial de enraizamento de estacas caulinares de Cestrum axillare e sua plasticidade morfoanatômica em condições de deficiência hídrica ou inundação do sistema radicular, para verificar sua potencialidade de utilização em projetos de recuperação de matas ciliares.

\section{MATERIAL E MÉTODOS}

Este trabalho foi desenvolvido em um período compreendido entre abril e setembro, no Viveiro Florestal do Departamento de Engenharia Florestal e no Departamento de Biologia, ambos na Universidade Federal de Lavras (UFLA), em Lavras - MG. Para o início dos experimentos foram utilizadas estacas caulinares de Cestrum axillare Vell., coletadas às margens do ribeirão Boa Vista, em Carmo da Mata, região Centro-Oeste de Minas Gerais, a 918 m de altitude, latitude 20³3'S e longitude 4452'W GRW.

\section{Enraizamento de estacas}

Para estudos de enraizamento utilizaram-se estacas caulinares de Cestrum axillare, separadas em quatro classes de diâmetro de base: 1) $5,0 \mathrm{~mm}$ (de 3,0 - 6,9 mm);2) 9,0 $\mathrm{mm}$ (de 7,0 - 10,9 mm); 3) $14,5 \mathrm{~mm}$ (de 11,0 - 17,9 mm) e 4) $24 \mathrm{~mm}$ (de 18,0 - $30 \mathrm{~mm}$ ), constituindo os quatro tratamentos. As estacas foram coletadas ao longo de ramos da planta-matriz, desde a base até $50 \mathrm{~cm}$ abaixo do ápice, sendo que os ápices dos ramos foram descartados, por estarem mais tenros e mais propícios à desidratação. Uma vez coletados os ramos, as estacas foram preparadas com dimensões de 15 a $20 \mathrm{~cm}$ de comprimento, sem folhas, 
realizando-se um corte em bisel na base. Desde a coleta até a chegada à casa de vegetação, as estacas foram mantidas túrgidas, em caixas de isopor, com o auxílio de aspersão por meio de um pulverizador durante um período de aproximadamente três horas.

O experimento foi desenvolvido em casa de vegetação climatizada com umidade em torno de $85 \%$ e temperatura entre 25 e $30^{\circ} \mathrm{C}$. Utilizaram-se tubetes com capacidade de $280 \mathrm{~cm}^{3}$ e substrato composto por uma mistura de $50 \%$ de terra de um Latossolo Vermelho Distrófico Típico (Tabela 1), coletada a aproximadamente $1 \mathrm{~m}$ de profundidade e $50 \%$ de areia lavada com granulometria média.

Com base no acompanhamento e observação do processo de enraizamento das estacas de Cestrum axillare, no $15^{\circ}$ dia após o estaqueamento, foi avaliado o percentual de estacas enraizadas e nestas, realizada a contagem do número de raízes e a medição da maior raiz formada por estaca. $O$ experimento foi conduzido em delineamento inteiramente casualizado, sendo cada tratamento formado por cinco repetições e dez estacas por parcela. Os dados encontrados para as características avaliadas foram submetidos à análise de variância, a 5\% de probabilidade de erro, sendo realizadas as análises de regressão com o auxílio do Programa Estatístico SisVar (FERREIRA, 2011).

\section{Características morfoanatômicas}

Para avaliação das modificações morfoanatômicas em plantas de Cestrum axillare foram utilizadas mudas com quatro meses de idade, obtidas a partir do processo de enraizamento anteriormente descrito. Para isso, mudas da classe de diâmetro de base 3 (14,5 mm de diâmetro médio, variando de 11,0 - 17,9 mm), após 30 dias de enraizamento, foram replantadas e cultivadas durante três meses em vasos com capacidade de $4000 \mathrm{~cm}^{3}$ ( $23 \mathrm{~cm}$ de altura e $15 \mathrm{~cm}$ de diâmetro), contendo a mesma formulação de substrato utilizada no enraizamento das estacas nos tubetes.

Foram esquematizados dois experimentos, deficit hídrico e inundação do sistema radicular, compostos por dois tratamentos cada (controle e submissão ao estresse). Os experimentos foram conduzidos em delineamento inteiramente casualizado, sendo cada tratamento composto por 12 vasos (parcelas), contendo uma planta cada. Para o experimento de deficit hídrico, os tratamentos foram separados em controle (irrigação diária) e deficiência hídrica (suspensão total da irrigação). O experimento persistiu até o décimo dia, quando da constatação de sintomas severos de murcha foliar, conforme realizado por Leles,

TABELA 1: Características químicas do solo.

TABLE 1: Chemical characteristics of soil.

\begin{tabular}{lcc}
\hline \multicolumn{1}{c}{ Características } & Valor & Unidade \\
\hline $\mathrm{pH}$ em água, $\mathrm{KCl}$ e $\mathrm{CaCl}_{2}$ - Relação1:2,5 & 5,4 & - \\
$\mathrm{P}$ - Extrator Mehlich1 & 0,7 & $\mathrm{mg} / \mathrm{dm}^{3}$ \\
$\mathrm{~K}$ - Extrator Mehlich1 & 23,0 & $\mathrm{mg} / \mathrm{dm}^{3}$ \\
$\mathrm{Ca}$ - Extrator: $\mathrm{KCl}-1 \mathrm{~mol} / \mathrm{L}$ & 0,4 & $\mathrm{cmol} / \mathrm{dm}^{3}$ \\
$\mathrm{Mg}$ - Extrator: $\mathrm{KCl}-1 \mathrm{~mol} / \mathrm{L}$ & 0,1 & $\mathrm{cmol} / \mathrm{dm}^{3}$ \\
$\mathrm{Al}$ - Extrator: $\mathrm{KCl}-1 \mathrm{~mol} / \mathrm{L}$ & 0,0 & $\mathrm{cmol} / \mathrm{dm}^{3}$ \\
$\mathrm{H}+\mathrm{Al}$ - Extrator: SMP & 1,9 & $\mathrm{cmol} / \mathrm{dm}^{3}$ \\
$\mathrm{SB}=\mathrm{Soma}$ de bases trocáveis & 0,6 & $\mathrm{cmol} / \mathrm{dm}^{3}$ \\
$\mathrm{CTC}$ (t) - Capacidade de troca catiônica efetiva & 0,6 & $\mathrm{cmol} / \mathrm{dm}^{3}$ \\
$\mathrm{CTC}$ (T) - Capacidade de troca catiônica a pH 7,0 & 2,4 & $\mathrm{cmol} / \mathrm{dm}^{3}$ \\
$\mathrm{~V}=$ Índice de saturação de bases & 23,2 & $\%$ \\
m = Índice de saturação de alumínio & 0,0 & $\%$ \\
Mat. Org. (MO) - Oxidação: $\mathrm{Na}_{2} \mathrm{Cr}_{2} \mathrm{O}_{7} 4 \mathrm{~N}+\mathrm{H}_{2} \mathrm{SO}_{4} 10 \mathrm{~N}$ & 0,8 & $\mathrm{dag} / \mathrm{kg}$ \\
P-rem = Fósforo remanescente & 1,3 & $\mathrm{mg} / \mathrm{L}$ \\
\hline
\end{tabular}


Carneiro e Barroso (1998). Ao fim do período experimental, os vasos foram novamente irrigados, a fim de verificar a resposta das plantas. Os efeitos da inundação do sistema radicular foram avaliados por meio da submissão das plantas a dois tratamentos: controle (irrigação diária) e inundação do sistema radicular (ISR). O ISR foi obtido por meio da inundação das plantas até a altura de 3-4 $\mathrm{cm}$ acima do colo, por um período de 40 dias. Neste experimento, os vasos foram transferidos para tanques de concreto $(300 \times 100 \times 60 \mathrm{~cm}$ de profundidade), forrados com lona plástica preta, nos quais foram submersos.

A morfologia externa das plantas, a abscisão foliar, a formação de lenticelas hipertrofiadas e de raízes adventícias foram avaliadas qualitativamente por meio de acompanhamento visual, durante todo o período experimental, em ambos os experimentos, enquanto as avaliações anatômicas foram realizadas ao final dos experimentos. Para o estudo anatômico, utilizaram-se cinco folhas completamente expandidas e o mesmo número de raízes por tratamento, oriundas de cinco plantas por tratamento, coletadas aleatoriamente. Para a coleta das raízes, o torrão contendo substrato e o sistema radicular das mudas foi retirado dos vasos, sendo em seguida lavado em água corrente. Após a coleta, os materiais foram fixos em formol/ácido acético/álcool (FAA) e conservados em etanol 70\%.

Nas folhas, as seções transversais foram obtidas por meio de cortes histológicos na região mediana das mesmas, com auxílio de micrótomo de mesa. Em seguida, as seções foram clarificadas com solução aquosa a $2 \%$ de hipoclorito de sódio, lavadas em água destilada (três vezes) para retirar o excesso de álcali e colocadas em solução aquosa a $1 \%$ de ácido acético. Utilizou-se a mistura de azul de astra e safranina para coloração, seguindo-se os métodos descritos por Kraus e Arduin (1997), sendo em seguida montadas lâminas semipermanentes, utilizando como meio de montagem glicerina a $50 \%$ em água.

As seções paradérmicas de folhas foram retiradas da região central do limbo foliar, sendo que para cada tratamento foram realizadas avaliações em quatro campos por folha e cinco folhas por tratamento. Essas seções foram obtidas à mão livre, com auxílio de lâmina de barbear; foram clarificadas de acordo com as mesmas técnicas utilizadas para as seções transversais. Utilizou-se o corante azul de toluidina $0,2 \%$, conforme metodologia utilizada por Chen e Gallie (2004). A contagem do número de estômatos ( $\mathrm{n}^{\mathrm{o}}$ de estômatos por $\mathrm{mm}^{2}$ de lâmina foliar) foi realizada com auxílio de câmara clara, em microscópio Olympus CCB, segundo técnica de Labouriau, Oliveira e Salgado-Labouriau (1961). As medições dos diâmetros equatorial e polar de estômatos (em $\mu \mathrm{m}$ ), e das espessuras dos tecidos do limbo foliar (em $\mu \mathrm{m})$ foram realizadas com auxílio de ocular micrometrada em microscópio Carl Zeiss Jena. Foram realizadas três medições da espessura das epidermes adaxial e abaxial, dos parênquimas paliçádico e esponjoso e da espessura total da lâmina foliar de cada folha.

As técnicas para confecção das lâminas para as seções de raízes seguiram as mesmas utilizadas para as seções transversais de folhas. Os cortes foram realizados na região da raiz em estrutura primária de crescimento, aproximadamente a $1 \mathrm{~cm}$ do ápice radicular.

Ao final das avaliações, seções foram fotomicrografadas, utilizando câmera digital acoplada ao microscópio Ken-A-Vision TT18 e os dados obtidos nas mensurações dos tecidos foram submetidos à análise de variância e teste de médias de Scott-Knott, a 5\% de probabilidade de erro.

\section{RESULTADOS E DISCUSSÃo}

\section{Enraizamento de estacas}

Aos quatro dias após o estaqueamento, já era possível observar o início de enraizamento das estacas de Cestrum axillare, demonstrando que a espécie apresenta facilidade em emitir raízes por meio da técnica utilizada. Quando este resultado é comparado a resultados obtidos em clones comerciais de eucalipto (FERREIRA et al., 2004; MELO et al., 2011), selecionados geneticamente e propagados de forma massal por meio da miniestaquia, pode-se observar que Cestrum axillare enraíza mais rapidamente. Além disso, ao final do período experimental, as estacas apresentaram $88 \%$ como média geral de enraizamento, não apresentando diferenças estatísticas entre as classes de diâmetro. Estes resultados corroboram os de Santos et al. (2011) que trabalhando com enraizamento de estacas de 20 espécies florestais nativas, dentre as quais Cestrum axillare (coerana), Salix humboldtiana (salgueiro), Maclura tinctoria (moreira), Croton urucurana (sangra d'água) e Tapirira guianensis (pombeiro), observaram que Cestrum axillare foi 
a espécie que apresentou o maior percentual de enraizamento (91\%). Resultados semelhantes, também, foram encontrados por Blum et al. (2013) ao observarem 91\% de enraizamento de estacas caulinares de Cestrum corymbosum (coerana-amarela) aos 90 dias após o estaqueamento.

Estacas das classes de maior diâmetro apresentaram maior número de raízes adventícias $(6,6 \mathrm{em}$ média) quando comparadas às estacas da classe de menor diâmetro $(3,0)$, sendo que a máxima eficiência técnica para o número de raízes adventícias seria alcançada em estacas com diâmetro médio da base de $18 \mathrm{~mm}$. Apesar das estacas das classes de maior diâmetro apresentarem mais raízes, o comprimento da maior raiz por estaca foi superior nas classes de menor diâmetro em relação às classes de maior diâmetro (Figura 1). Aos 15 dias após o estaqueamento, as estacas já apresentavam raízes com comprimento de 6,0 $\mathrm{cm}$ (Figura 1), ao passo que Valeri et al. (2012), avaliando o enraizamento de estacas obtidas de mudas jovens de Caesalpinia echinata (pau-brasil), verificaram que, somente depois de decorridos 90 dias do estaqueamento, as raízes apresentavam comprimento aproximado de $6,0 \mathrm{~cm}$. Mais contrastantes foram os resultados de Althaus-Ottmann, Leal e Zuffellato-Ribas (2006), que ao avaliarem o comprimento médio das três maiores raízes por estaca de Brunfelsia uniflora (manacá), outra espécie de Solanaceae, após 120 dias do estaqueamento, verificaram que, no melhor tratamento, as raízes apresentavam $1,14 \mathrm{~cm}$ de comprimento.

O enraizamento diferenciado de estacas tem sido diretamente relacionado ao seu balanço hormonal endógeno, especialmente a balanços favoráveis à ação de auxinas, os quais podem ser variáveis em diferentes diâmetros, em decorrência da distância da parte do caule cortada em relação ao ápice caulinar, seu principal sítio de síntese (OLIVEIRA; NIENOW; CALVETE, 2003; CHENG et al., 2013). No entanto, segundo os resultados obtidos neste trabalho, é possível constatar que Cestrum axillare apresenta altos percentuais de enraizamento, independentemente do diâmetro das estacas e, consequentemente, da distância da parte do ramo cortada em relação ao ápice caulinar.
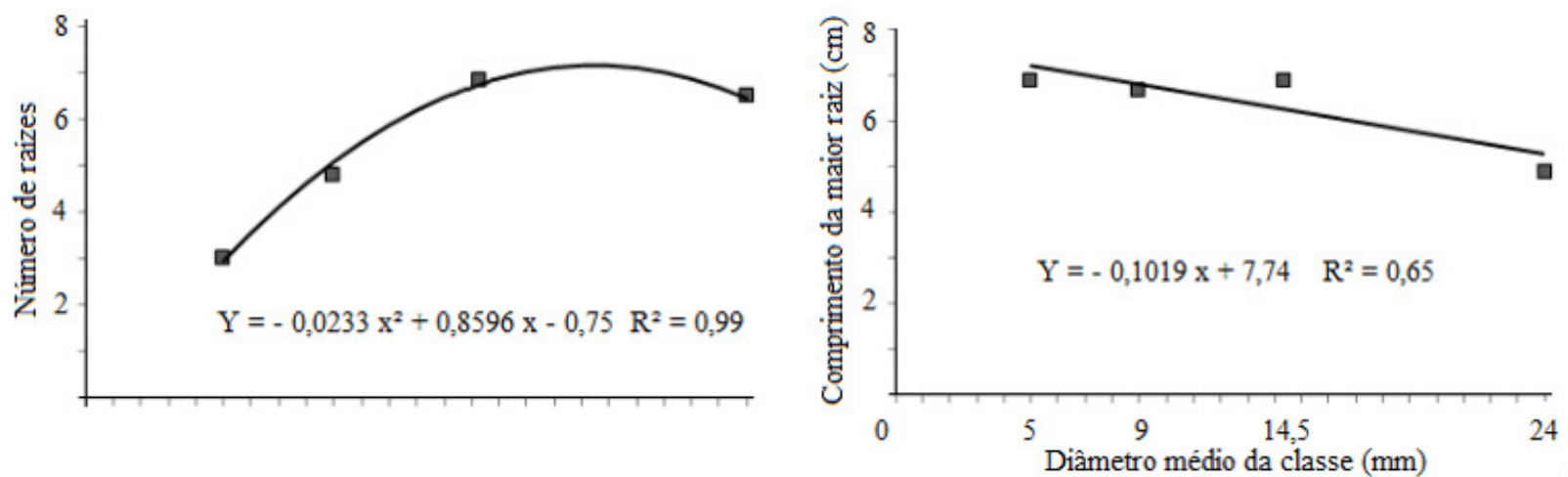

FIGURA 1: Número de raízes e comprimento da maior raiz em mudas de Cestrum axillare Vell. (coerana), aos 15 dias após o estaqueamento, em função do diâmetro médio das estacas caulinares.

FIGURE 1: Number of roots and major root length in Cestrum axillare Vell. (coerana), 15 days after staking, depending on the average diameter of stem cuttings.

\section{Características morfoanatômicas}

\section{Submissão à deficiência hídrica}

Plantas submetidas ao tratamento de deficiência hídrica apresentaram clorose das folhas, observada visualmente, a partir do quarto dia de suspensão total da irrigação, enquanto a murcha permanente foliar foi observada no décimo dia de tratamento (Figura 2A). Resultados semelhantes aos observados neste estudo em relação à clorose e à murcha foliar, ocorridos nas plantas sob deficiência de água, foram obtidos por Leles, Carneiro e Barroso (1998), estudando o comportamento de mudas de Apuleia leiocarpa (garapa) e Hymenaea courbaril (jatobá), produzidas sob três regimes de irrigação (irrigação diária, irrigação após o aparecimento inicial de sintomas de murcha foliar ou irrigação após o surgimento dos sintomas severos de murcha foliar). No entanto, segundo os autores, os sintomas iniciais de murcha foliar das mudas de garapa 


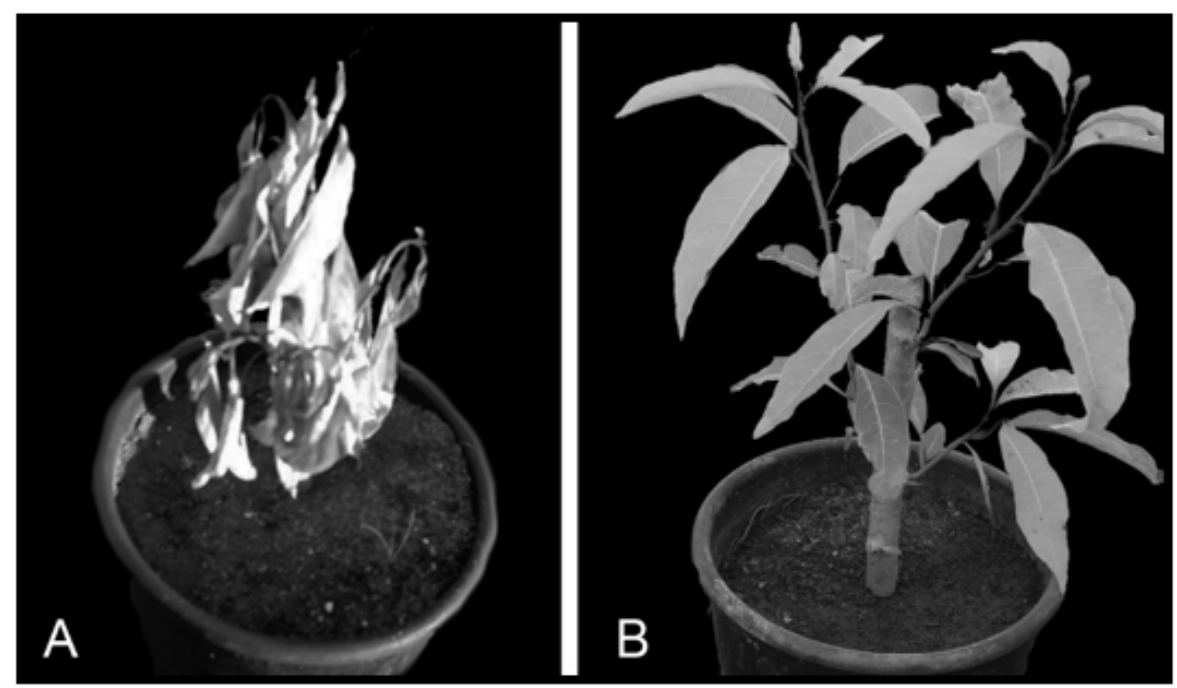

FIGURA 2: Cestrum axillare Vell. (coerana) submetida à suspensão da irrigação. A: Muda aos dez dias de suspensão da irrigação; B: Muda irrigada após ter passado pelo período de dez dias com suspensão da irrigação.

FIGURE 2: Cestrum axillare Vell. (coerana) submitted the suspension of watering. A: seedling at the tenth day of watering suspension; B: Seedling irrigated after having gone by the period of ten days with suspension of watering.

e de jatobá foram visualizados, respectivamente, aos três e sete dias após suspender a irrigação, indicando que as espécies apresentam diferentes graus de tolerância à deficiência hídrica.

Ao final do período experimental, plantas sob deficiência hídrica apresentaram maior espessura da epiderme da face adaxial, do parênquima esponjoso, da epiderme da face abaxial e da espessura total do limbo foliar em relação às plantas do tratamento-controle (irrigação diária) (Tabela 2). Por meio de seções paradérmicas da epiderme foliar da face abaxial não foram observadas diferenças significativas para a densidade estomática de plantas submetidas ao tratamento de deficit hídrico e seu controle, assim como para o diâmetro equatorial de estômatos. No entanto, plantas submetidas ao estresse apresentaram diâmetro polar dos estômatos menor que plantas submetidas ao tratamento-controle (Tabela 2).

Quanto às mudanças anatômicas em estômatos, sabe-se que o aumento da densidade e/ou a redução no tamanho dos estômatos são fatores reconhecidamente importantes para adaptabilidade ou tolerância de plantas a diferentes condições adversas ao seu desenvolvimento. Isso porque folhas com estômatos que

TABELA 2: Densidade estomática $\left(\mathrm{n}^{\mathrm{o}}\right.$ de estômatos por $\left.\mathrm{mm}^{2}\right)$, tamanho dos estômatos $(\mu \mathrm{m})$, espessura $(\mu \mathrm{m})$ de tecidos do mesofilo e limbo foliar de Cestrum axillare Vell., (coerana), após dez dias com suspensão da irrigação.

TABLE 2: Stomatic Density ( $\mathrm{n}^{\mathrm{o}}$ of stomach $\left./ \mathrm{mm}^{2}\right)$, stomach size $(\mu \mathrm{m})$, thickness $(\mu \mathrm{m})$ of mesophyll tissue and leaf blades of Cestrum axillare Vell., (coerana), after ten days with suspension of watering.

\begin{tabular}{lcccccccc}
\hline \multicolumn{1}{c}{ Tratamento } & DEAb & DPE & DEE & EEAd & EPP & EPE & EAb & ETL \\
\hline Controle & $178 \mathrm{a}$ & $39,73 \mathrm{~b}$ & $24,19 \mathrm{a}$ & $30,66 \mathrm{a}$ & $49,28 \mathrm{a}$ & $116,44 \mathrm{a}$ & $19,71 \mathrm{a}$ & $216,08 \mathrm{a}$ \\
Estresse & $157 \mathrm{a}$ & $36,06 \mathrm{a}$ & $25,07 \mathrm{a}$ & $36,50 \mathrm{~b}$ & $54,02 \mathrm{a}$ & $139,07 \mathrm{~b}$ & $22,27 \mathrm{~b}$ & $251,85 \mathrm{~b}$ \\
\hline
\end{tabular}

Em que: DEAb $=$ Densidade estomática da epiderme da face abaxial; DPE = Diâmetro polar dos estômatos da epiderme da face abaxial; DEE = Diâmetro equatorial dos estômatos da epiderme da face abaxial; EEAd = Espessura da epiderme da face adaxial; EPP = Espessura do parênquima paliçádico; $\mathrm{EPE}=$ Espessura do parênquima esponjoso; $\mathrm{EAb}=$ Espessura da epiderme da face abaxial; $\mathrm{ETL}=$ Espessura total do limbo foliar. Médias seguidas da mesma letra, na coluna, não diferem entre si pelo teste de Scott-Knott, a 5\% de probabilidade de erro. 
apresentam menor abertura dos ostíolos têm maior eficiência no uso da água, em decorrência de uma menor transpiração (MELO et al., 2007), sem, no entanto, prejudicar a absorção de $\mathrm{CO}_{2}$ necessário ao processo carboxilativo da fotossíntese, uma vez que o grau de abertura estomática provoca maior efeito sobre a difusão de água do que sobre a difusão do $\mathrm{CO}_{2}$ (BIDWELL, 1964). Embora trabalhos tenham mostrado que inúmeras espécies, quando submetidas a uma condição de deficit hídrico, tendem a aumentar a densidade estomática e/ou diminuírem o tamanho de seus estômatos (SILVA et al., 1999; NASCIMENTO, 2003; MELO et al., 2007; MORATELLI et al., 2007; RIBEIRO et al., 2012), o comportamento não diferenciado apresentado por Cestrum axillare quanto à densidade estomática já era esperado devido às avaliações terem sido realizadas em folhas já completamente desenvolvidas durante a condução do experimento. No entanto, o diâmetro polar desses estômatos na epiderme abaxial apresentou uma redução, fator este importante para o tamanho da abertura do ostíolo, e que consequentemente, favorece uma menor perda de água por transpiração. A redução da taxa de transpiração, por sua vez, é um fator fundamental ao aumento da tolerância de plantas a um ambiente com restrição hídrica (PLAUT et al., 2013)

O aumento na espessura de parênquimas e lâmina foliar como um todo em condição de deficiência hídrica, conforme observado neste trabalho, apesar de ter sido avaliado em folhas desenvolvidas previamente ao estresse (Tabela 2), é um sinal positivo de tolerância a esta condição e, geralmente, pode estar associado a uma redução na área foliar. Estes fatores podem reduzir os processos oxidativos celulares, por favorecer que organelas, como os cloroplastos, evitem a radiação excessiva, a qual geralmente está associada à condição de deficiência hídrica, e também, por promover melhor dissipação térmica (DE MICCO et al., 2011). Um aumento quantitativo desses parâmetros também pode ser observado em diferentes espécies como Manihot esculenta (mandioca) e Olea europaea (oliveira), especialmente ao se comparar cultivares mais tolerantes à deficiência hídrica àquelas menos tolerantes (ENNAJEH et al., 2010; RIBEIRO et al., 2012).

No entanto, a plasticidade de tecidos do mesofilo à condição de estresse tem uma forte modulação do genótipo em questão. Em um estudo com Mikania glomerata (guaco), plantas submetidas ao estresse severo (irrigação suspensa) apresentaram os menores valores de espessuras do parênquima paliçádico e esponjoso, provavelmente devido à perda do volume celular como resultado da perda excessiva de água e desidratação. Se as plantas murcham, suas células se contraem com a diminuição proporcional do volume celular (NASCIMENTO, 2003). Melo et al. (2007) observaram resultados semelhantes em Setaria anceps (capim-marangá), a qual apresentou os menores valores médios de espessura do limbo foliar em tratamentos conduzidos sob baixa disponibilidade de água $(227 \mu \mathrm{m})$, em comparação aos valores médios de espessura do limbo foliar no tratamento-controle $(259 \mu \mathrm{m})$. No entanto, embora possa não ser significativo para o órgão folha como um todo, é conhecido que algumas plantas sob estresse, inclusive hídrico, possam aumentar a espessura da parede periclinal externa da epiderme e cutícula (ROÇAS; SCARANO; BARROS, 2001; WALDHOFF, 2003), provavelmente como uma forma de reduzir a transpiração cuticular (LARCHER, 2000).

Após o período de suspensão total da irrigação (dez dias), as mudas de Cestrum axillare submetidas ao deficit hídrico foram irrigadas, voltando seus órgãos à normalidade de turgescência característica da espécie, seguida do crescimento das plantas (Figura 2B). Espécies que consigam tolerar essas intempéries possuem chances maiores de sobreviver em ocasiões com restrição de água em ambientes naturais. Além disso, segundo Larcher (2000), geralmente, a maioria das plantas morre mais rapidamente em uma situação de inundação do que de deficiência hídrica no solo.

\section{Submissão à inundação do sistema radicular}

No experimento de inundação do sistema radicular observou-se que entre o quarto e sexto dia após a inundação das mudas, ocorreu um aumento no aparecimento de lenticelas hipertrofiadas no caule das plantas submetidas à submersão do sistema radicular (Figura 3.1), enquanto a formação de raízes adventícias sobre a superfície do substrato ocorreu a partir do sétimo dia de submersão das plantas. As novas raízes formadas apresentavam-se com diâmetros maiores, esponjosas e quebradiças, quando comparadas com as demais raízes do sistema radicular original do mesmo indivíduo. A maior porosidade das raízes permite, não só mais fácil absorção de água e nutrientes, o transporte interno de oxigênio, como a liberação deste ao meio, buscando a necessária oxigenação da rizosfera (ABREU; CAMPOS NETTO; BARROS, 1993; 
CALHEIROS, 2000; PIRES; SOPRANO; CASSOL, 2002).

Além dessas mudanças, plantas inundadas apresentaram abscisão foliar logo no início da submissão ao tratamento e até, aproximadamente, o $30^{\circ}$ dia, todas as mudas sob inundação do sistema radicular cessaram seu crescimento, deixando de lançar novas brotações. No entanto, a espécie tolerou a condição imposta e as plantas retornaram seu crescimento vegetativo após este período, sendo um bom indicativo de que Cestrum axillare pode ser utilizada em projetos de recuperação de ambientes em que ocorrem condições similares às testadas neste estudo.

Durante todo o período experimental, lenticelas hipertrofiadas foram observadas e raízes adventícias cresceram sob a superfície da lâmina de água. Este resultado indica que mesmo em um solo completamente inundado, o oxigênio pode não estar totalmente ausente, existindo concentrações consideráveis nas camadas próximas à superfície da água, permitindo assim, que as plantas sobrevivam nestes solos, utilizando estratégias morfológicas e/ou metabólicas para superar esta condição de estresse, tais como a presença do hipertrofiamento lenticelar e a formação de raízes adventícias na camada imediatamente inferior à lâmina de água (KOZLOWISKI, 1984; CALHEIROS, 2000; MELO et al., 2004).

As raízes de Cestrum axillare possuem em seu córtex tecidos aerenquimáticos constitutivos, conforme observado pelas seções transversais de raízes de plantas do tratamento-controle, ou seja, que não foram submetidas à inundação do sistema radicular (Figura 3.2A). No entanto, em raízes sob inundação, observou-se que a área deste tecido aumentou consideravelmente quando comparada à área de aerênquima

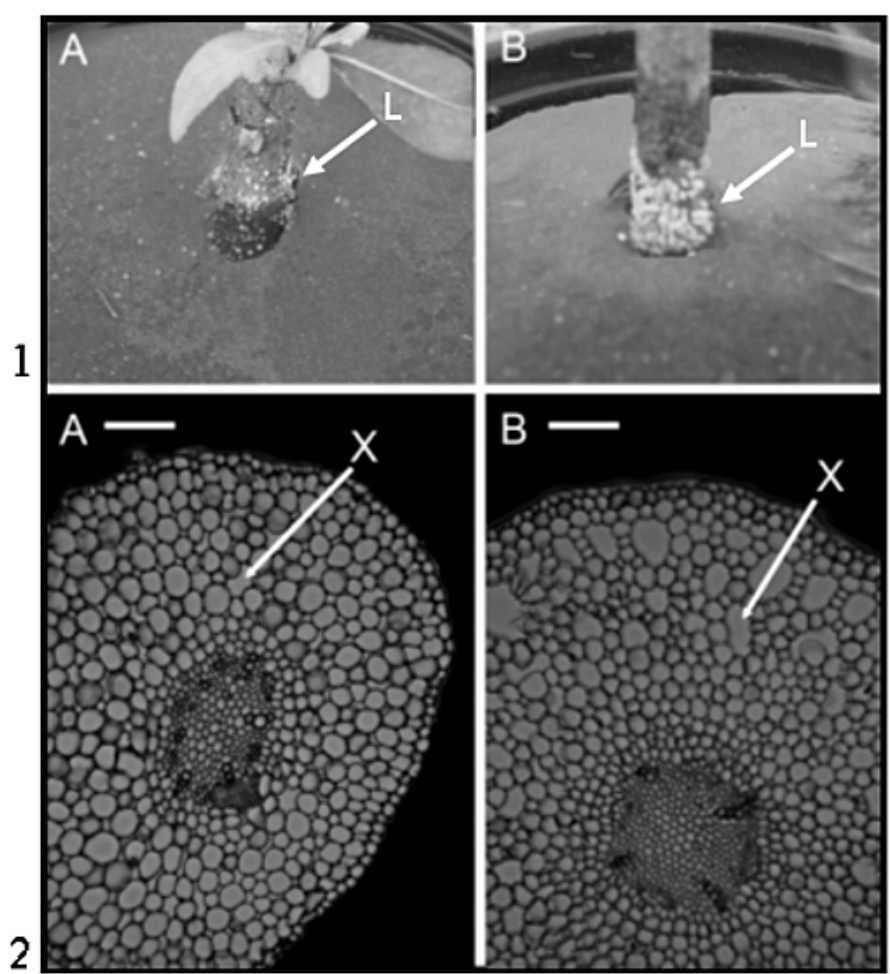

FIGURA 3: Mudas de Cestrum axillare Vell. (coerana) submetidas à inundação do sistema radicular (1); Seções transversais da raiz, em estrutura primária (2). 1A: Cinco dias de submissão das plantas à inundação do sistema radicular; 1B: 40 dias de submissão das plantas à inundação do sistema radicular. L: lenticelas hipertrofiadas; 2A: Controle (40 dias); 2B: Planta sob inundação do sistema radicular (40 dias); X: Aerênquima. Barra: $100 \mu \mathrm{m}$.

FIGURE 3: Cestrum axillare Vell. (coerana) seedling submitted to inundation of root system. (2); Root cross-section, in primary structure (1). 1A: Five days of submission to root system inundation; 1B: 40 days of submission to root system inundation. L: hypertrophy of the lenticels; 2A: Control (40 days); 2B: Plant after root system inundation (40 days); X: Aerenchyma. Bar: $100 \mu \mathrm{m}$. 
TABELA 3: Densidade estomática (n. de estômatos $/ \mathrm{mm}^{2}$ ), tamanho dos estômatos $(\mu \mathrm{m})$, espessura $(\mu \mathrm{m})$ de tecidos do mesofilo e limbo foliar de Cestrum axillare Vell. (coerana), após 40 dias de submissão das plantas à inundação do sistema radicular.

TABLE 3: Stomatic Density (n. of stomach $/ \mathrm{mm}^{2}$ ), stomach size $(\mu \mathrm{m})$, thickness $(\mu \mathrm{m})$ of mesophyll tissue and leaf blades of Cestrum axillare Vell. (coerana), after 40 days of submission to root system inundation.

\begin{tabular}{ccccccccc}
\hline Tratamento & DEAb & DPE & DEE & EEAd & EPP & EPE & EAb & ETL \\
\hline Controle & $213 \mathrm{a}$ & $32,99 \mathrm{a}$ & $21,70 \mathrm{a}$ & $28,84 \mathrm{a}$ & $83,95 \mathrm{~b}$ & $114,25 \mathrm{a}$ & $20,08 \mathrm{a}$ & $248,20 \mathrm{~b}$ \\
Estresse & $252 \mathrm{~b}$ & $34,89 \mathrm{~b}$ & $21,99 \mathrm{a}$ & $29,20 \mathrm{a}$ & $59,86 \mathrm{a}$ & $118,26 \mathrm{a}$ & $19,71 \mathrm{a}$ & $227,40 \mathrm{a}$ \\
\hline
\end{tabular}

Em que: DEAb = Densidade estomática da epiderme da face abaxial; DPE = Diâmetro polar dos estômatos da epiderme da face abaxial; DEE $=$ Diâmetro equatorial dos estômatos da epiderme da face abaxial; EEAd $=$ Espessura da epiderme da face adaxial; EPP = Espessura do parênquima paliçádico; EPE = Espessura do parênquima esponjoso; $\mathrm{EAb}=$ Espessura da epiderme da face abaxial; $\mathrm{ETL}=$ Espessura total do limbo foliar. Médias seguidas da mesma letra, na coluna, não diferem entre si pelo teste de Scott-Knott, a 5\% de probabilidade de erro.

em raízes não submersas. Além das mudanças em relação à proporção de aerênquimas, pode-se notar que raízes de plantas sob inundação do sistema radicular possuem diâmetro maior que raízes de plantas do tratamento-controle e apresentam duas camadas de células epidérmicas (Figura 3.2B), aumentando assim a habilidade que a espécie possui em responder rapidamente a situações de hipoxia. Desta forma, pelos resultados obtidos, a presença de aerênquimas, aliada ao hipertrofiamento lenticelar e à formação de raízes adventícias em plantas submetidas à inundação, provavelmente tenham sido os principais fatores que condicionaram a tolerância desta espécie ao ambiente inundado.

Aos 40 dias de submissão das plantas à inundação do sistema radicular, foram verificadas inúmeras diferenças quanto às estruturas foliares. Para características relativas aos estômatos, o diâmetro polar em plantas submetidas ao estresse foi superior quando comparadas ao de plantas do tratamento-controle. O mesmo resultado foi observado para a densidade estomática (Tabela 3). A espessura do limbo foliar foi influenciada pela espessura do parênquima paliçádico, sendo que plantas do tratamento-controle apresentaram limbo foliar mais espesso em relação às plantas do tratamento ISR (Tabela 3).

Mudanças observadas na densidade e tamanho de estômatos, assim como na espessura de tecidos do mesofilo ou da lâmina foliar, de uma maneira geral, eram esperadas, uma vez que foram analisadas em folhas desenvolvidas durante o período experimental, o que expressa a plasticidade da espécie em responder morfologicamente às mudanças do meio. Souza et al. (2010) destacam que as mudanças na redução dos tecidos que compõem a lâmina foliar, em plantas alagadas, são resultado da diminuição quantitativa de tecidos esclerenquimáticos. Essa resposta também pode estar associada ao aumento da área foliar em consequência da diminuição da radiação, que geralmente ocorre concomitantemente à maior precipitação nas condições naturais do ambiente.

Embora o aumento de densidade estomática esteja geralmente associado à condição de deficiência hídrica, plantas tolerantes ao alagamento também podem ter essa mesma resposta, uma vez que a planta tende a promover maior fechamento estomático devido a um aumento na síntese de ácido abscísico em condições de alagamento (BAI et al., 2013). Assim, um aumento na densidade estomática contribui para a manutenção de absorção de dióxido de carbono necessário às reações carboxilativas da fotossíntese.

\section{CONCLUSÕES}

Cestrum axillare pode ser propagada pela técnica de estaquia, pois apresenta enraizamento médio de $88 \%$ dos propágulos após 15 dias de seu estaqueamento. Aliado ao potencial de enraizamento de estacas, plantas de Cestrum axillare desenvolvem rapidamente alterações morfoanatômicas com potencial de conferir tolerância às condições de estresses hídricos, tais como, a redução do diâmetro polar dos estômatos em folhas de plantas submetidas à deficiência hídrica, a formação de raízes adventícias, o hipertrofiamento 
lenticelar e o aumento de aerênquima nas raízes.

Portanto, Cestrum axillare é uma espécie indicada para ser utilizada em projetos de recuperação de matas ciliares, tendo em vista que sua plasticidade e seu comportamento com relação a diversos parâmetros morfoanatômicos são condizentes àqueles que promovem tolerância de plantas submetidas a essas condições ambientais.

\section{REFERÊNCIAS}

ABREU, C. A.; CAMPOS NETTO, R. B.; BARROS, N. F. Crescimento de mudas de quatro espécies de eucalipto sob condições de solo inundado. Revista Árvore, Viçosa, MG, v. 17, n. 1, p. 1-9, jan./mar. 1993. ALTHAUS-OTTMANN, M. M.; LEAL, L.; ZUFFELLATO-RIBAS, K. C. Propagação vegetativa de manacá (Brunfelsia uniflora (Pohl.) D. Don). Revista Brasileira de Horticultura Ornamental, Jundiaí, v. 12, n. 1, p. 31-36, jan./jun. 2006.

ANDRADE, L. A. et al. Análise florística e estrutural de matas ciliares ocorrentes em brejo de altitude no município de Areia, Paraíba. Revista Brasileira de Ciências Agrárias, Recife, v. 1, n. 1, p. 31-40, jul./dez. 2006.

BAI, T. et al. Contrasting hypoxia tolerance and adaptation in Malus species is linked to differences in stomatal behavior and photosynthesis. Physiologia Plantarum, Copenhagem, v. 147, n. 4, p. 514-523, abr. 2013.

BIDWELL, R. G. S. Protein synthesis and turn over in cultured plant tissue: sources of carbon and the fate of the protein breakdown products. Nature, Londres, v. 203, n. 494, p. 367-373, 1964.

BLUM, C. T. et al. Propagação de Cestrum corymbosum por sementes e estaquia. Floresta, Curitiba, v. 43, n. 1, p. 137-144, jan./mar. 2013.

CALHEIROS, R. O. Efeito do manejo da água de drenagem na adaptação de plantas mesófitas ao encharcamento. 2000. 127 f. Tese (Doutorado em Irrigação e Drenagem) - Escola Superior de Agricultura Luiz de Queiroz, Piracicaba, 2000.

CALLEGARO, R. M. et al. Regeneração natural avançada de um fragmento de mata ciliar em Jaguari, RS, Brasil. Revista Brasileira de Ciências Agrárias, Pernambuco, v. 7, n. 2, p. 315-321, abr./jun. 2012.

CASEMIRO, E. L. N.; MALAVASI, U. C.; MALAVASI, M. M. Efeitos da saturação hídrica, idade e volume radicular no crescimento inicial de quatro espécies florestais. Revista Floresta e Ambiente, Seropédica, v. 15, n. 1, p. 13-19, jan./mar. 2008.

CASTRO, M. N.; CASTRO, R. M.; SOUZA, P. C. A importância da mata ciliar no contexto da conservação do solo. Revista Eletrônica de Educação da Faculdade Araguaia, Goiânia, v. 4, n. 1, p. 230-241, jan./jun. 2013.

CHEN, Z.; GALLIE, D. R. The ascorbic acid redox state controls guard cell signaling and stomatal movement. The Plant Cell, Rockville, v. 16, n. 4, p. 1143-1162, abr. 2004.

CHENG, Z. J. et al. Pattern of auxin and cytokinin responses for shoot meristem induction results from the regulation of cytokinin biosynthesis by auxin response fator. Plant Physiology, Rockville, v. 161, n. 1, p. 240-251, jan. 2013.

DAVANSO, V. M. et al. Photosynthesis, growth and development of Tabebuia avellanedae Lor. Ex Griseb. (Bignoniaceae) in flooded soil. Brazilian Archives of Biology and Technology, Curitiba, v. 45, n. 3, p. 375-384. jul./set. 2002.

DE MICCO, V. Anatomy and photochemical behaviour of Mediterranean Cistus incanus winter leaves under natural outdoor and warmer indoor conditions. Botany, Ottawa, v. 89, n. 10, p. 677-688, out. 2011.

DIAS, P. C. et al. Estaquia e miniestaquia de espécies florestais lenhosas do Brasil. Pesquisa Florestal Brasileira, Colombo, v. 32, n. 72, p. 453-462, out./dez. 2012.

DOSMANN, M. S. et al. Drought avoidance in Katsura by drought-induced leaf abscission and rapid refoliation. HortScience, Alexandria, v. 34, n. 5, p. 871-874, ago. 1999.

ENNAJEH, M. et al. Comparative impacts of water stress on the leaf anatomy of a drought-resistant and a drought-sensitive olive cultivar. Journal of Horticultural Science \& Biotechnology, Dundee, v. 85, n. 4, p. 289-294, set./out. 2010.

FERREIRA, D. A. C.; DIAS, H. C. T. Situação atual da mata ciliar do ribeirão São Bartolomeu em Viçosa, 
MG. Revista Árvore, Viçosa, MG, v. 28, n. 4, p. 617-623, set./out. 2004.

FERREIRA, D. F. Sisvar: a computer statistical analysis system. Ciência e Agrotecnologia, Lavras, v. 35, n. 6, p. 1039-1042, nov./dez. 2011.

FERREIRA, E. M. et al. Determinação do tempo ótimo do enraizamento de miniestacas de clones de Eucalyptus spp. Revista Árvore, Viçosa, MG, v. 28, n. 2, p. 183-187, mar./abr. 2004.

KOZLOWISKI. T. T. Responses of woody plants to flooding. In: KOZLOWSKI. T.T. (Ed.). Flooding and plant growth. Madison: Wisconsin, 1984. p. 129-163.

KRAUS, J. E.; ARDUIN, M. Manual básico de métodos em morfologia vegetal. Seropédica: EDUR, 1997.

KREUZWIESER, J.; RENNENBERG, H. Molecular and physiological responses of trees to waterlogging stress. Plant, Cell and Environment, New York, v. 37, p. 2245-2259, 2014.

LABOURIAU, L. G.; OLIVEIRA, J. G.; SALGADO-LABOURIAU, M. L. Transpiração de Schizolobium parahyba (Vell) Toledo I. comportamento na estação chuvosa, nas condições de Caeté, Minas Gerais. Anais da Academia Brasileira de Ciências, Rio de Janeiro, v. 23, n. 2, p. 237-257, abr.jun. 1961.

LARCHER, W. Ecofisiologia vegetal. São Carlos: Rima, 2000. 531 p.

LELES, P. S. S.; CARNEIRO, J. G. A.; BARROSO, D. G. Comportamento de mudas de Hymenaea courbaril L. var. stilbocarpa (Hayne) e Apuleia leiocarpa (Vog.) Macbr. produzidas sob três regimes de irrigação. Revista Árvore, Viçosa, MG, v. 22, n. 1, p. 11-19, jan./mar. 1998.

MAES, W. H. et al. Plant-water relationships and growth strategies of Jatropha curcas L. seedlings under different levels of drought stress. Journal of Arid Environments, London, v. 73, n. 10, p. 877-884, out. 2009.

MARINHO, T. A. S. et al. Distribuição e crescimento de Garcinia brasiliensis Mart. e Hevea spruceana (Benth.) Müll. Arg. em uma floresta inundável em Manaus, Amazonas. Revista Ciência Florestal, Santa Maria, v. 23, n. 1, p. 223-232, jan./mar. 2013.

MEDRI, M. E. et al. Aspectos morfoanatômicos e fisiológicos de Peltophorum dubium (Spr.) Taub. submetida ao alagamento e à aplicação de etrel. Revista Brasileira de Botânica, São Paulo, v. 21, n. 3, p. 261-267, dez. 1998.

MELO, H. C. et al. Alterações anatômicas e fisiológicas em Setaria anceps Stapf ex Massey e Paspalum paniculatum L. sob condições de déficit hídrico. Hoehnea, São Paulo, v. 34, n. 2, p. 145-153, abr.jun. 2007. MELO, H. C. et al. Influência da aplicação de cálcio e alagamento do solo sobre as características anatômicas das folhas de milho (Zea mays L.) "Saracura" BRS-4154. Revista Brasileira de Milho e Sorgo, Sete Lagoas, v. 3, n. 3, p. 333-342, set./dez. 2004.

MELO, L. A. et al. Otimização do tempo necessário para o enraizamento de miniestacas de clones híbridos de Eucalyptus grandis. Revista Árvore, Viçosa, MG, v. 35 n. 4, p. 759-767, jul./ago. 2011.

MORATELLI, E. M. et al. Efeito da disponibilidade de água e de luz na colonização micorrízica e no crescimento de Tabebuia avellanedae Lorentz ex Griseb. (Bignoniaceae). Revista Árvore, Viçosa, MG, v. 31, n. 3, p. 555-566, set./out. 2007.

NASCIMENTO, C. F. Aspectos anatômicos, fisiológicos e fitoquímicos de plantas jovens de Mikania glomerata Sprengel (guaco) submetidas a diferentes regimes hídricos. 2003. 68 f. Dissertação (Mestrado em Fisiologia Vegetal) - Universidade Federal de Lavras, Lavras, 2003.

OLIVEIRA, A. P.; NIENOW, A. A.; CALVETE, E. O. Capacidade de enraizamento de estacas semilenhosas e lenhosas de cultivares de pessegueiro tratadas com AIB. Revista Brasileira de Fruticultura, Jaboticabal, v. 25, n. 2, p. 282-285, mai./ago. 2003.

PAROLIN, P. Morphological and physiological adjustments to waterlogging and drought in seedlings of Amazonian floodplain trees. Oecologia, New York, v. 128, n. 3, p. 326-335, ago. 2001.

PAULA, S. R. P.; PAIVA, A. V.; MARANHO, A. S. Transposição de plântulas de Alchornea castaneifolia (Willd.) A. Juss. como estratégia de produção de mudas em viveiro. Cerne, Lavras, v. 19, n. 2, p. 323-330, abr./jun. 2013.

PINTO, L. V. A. et al. Estudo da vegetação como subsídios para propostas de recuperação das nascentes da bacia hidrográfica do Ribeirão Santa Cruz, Lavras, MG. Revista Árvore, Viçosa, MG, v. 29, n. 5, p. 775-793, set./out. 2005.

PIRES, J. L. F.; SOPRANO, E.; CASSOL, B. Adaptações morfofisiológicas da soja em solo inundado. 
Pesquisa Agropecuária Brasileira, Brasília, v. 37, n. 1, p. 41-50, jan. 2002.

PLAUT, J. A. et al. Reduced transpiration response to precipitation pulses precedes mortality in a pinonjuniper woodland subject to prolonged drought. New Phytologist, Boston, v. 200, n. 2, p. 375-387, out. 2013.

RENNENBERG, H. et al. Physiological responses of forest trees to heat and drought. Plant Biology, New York, v. 8, n. 5, p. 556-571, jun. 2006.

RIBEIRO, M. N. O. et al. Anatomia foliar de mandioca em função do potencial para tolerância à diferentes condições ambientais. Revista Ciência Agronômica, Fortaleza, v. 43, n. 2, p. 354-361, abr./jun. 2012.

ROÇAS, G.; SCARANO, F. R.; BARROS, C. F. Leaf anatomical variation in Alcornea triplinervia (Euphorbiaceae) under distints light and soil water regimes. Botanical Journal of the Linnean Society, Londres, v. 136, n. 2, p. 231-238, jun. 2001.

SANTARELLI, E. G. Recuperação de mata ciliar: seleção de espécies e técnicas de implantação. In: BALENSIEFER, M. Recuperação de áreas degradadas: III curso de atualização. Curitiba: FUPEF, 1996. p. 101-105.

SANTOS, J. P. et al. Enraizamento de estacas lenhosas de espécies florestais. Cerne, Lavras, v. 17, n. 3, p. 293-301, jul./set. 2011.

SANTOS, M.Q.C. et al.Rooting soft cuttings of soursop (Annona muricata) 'GIANT OF ALAGOAS'. Acta Horticulturae, Wageningen, v. 923, p. 241-245, 2011.

SANTOS, S. R. Q. Regime térmico e hídrico do solo para área de floresta tropical em anos de El Niño e La Niña, Caxiuanã-PA: estudo de caso. Revista Brasileira de Meteorologia, São Paulo, v. 26, n. 3, p. 367-374, set. 2011.

SILVA, H. et al. Efecto del déficit hídrico en la anatomía foliar de seis cultivares de poroto Phaseolus vulgaris. Revista Chilena de Historia Natural, Santiago, v. 72, n. 2, p. 219-235, abr./jun. 1999.

SILVA, S. et al. Respostas fisiológicas de gramíneas promissoras para revegetação ciliar de reservatórios hidrelétricos, submetidas à deficiência hídrica. Ciência e Agrotecnologia, Lavras, v. 25, n. 1, p. 124-133, jan./fev. 2001.

SOUZA, T. C. et al. Leaf plasticity in successive selection cycles of 'Saracura' maize in response to periodic soil flooding. Pesquisa Agropecuária Brasileira, Brasília, v. 45, n. 1, p. 16-24, jan. 2010.

STEHMANN, J. R. et al. Solanaceae in Lista de espécies da flora do Brasil. Jardim Botânico do Rio de Janeiro. Disponível em: <http://floradobrasil.jbrj.gov.br/jabot/floradobrasil/FB14636>. Acesso em: 18 mai. 2014.

SUTILI, F. J. et al. Potencial biotécnico do sarandi-branco (Phyllanthus sellowianus Müll. Arg.) e vime (Salix viminalis L.) para revegetação de margens de cursos de água. Ciência Florestal, Santa Maria, v. 14, n. 1, p. 13-20, jan./mar. 2004.

VALERI, S. V. et al. Enraizamento de estacas de Caesalpinia echinata Lam. em hidroponia. Ciência Florestal, Santa Maria, v. 22, n. 2, p. 241-250, abr./jun. 2012.

WALDHOFF, D. Leaf structure in trees of Central Amazonian floodplain forests (Brazil). Amazoniana, Manaus, v. 17 n. 3, p. 451-469, jun. 2003.

WANG, G. B.; CAO, F. L. Formation and function of aerenchyma in baldcypress (Taxodium distichum (L.) Rich.) and Chinese tallow tree (Sapium sebiferum (L.) Roxb.) under flooding. South African Journal of Botany, Pietermaritzburg, v. 18, p. 71-78, jul. 2012. 